SCIENTIFIC REPORT

\title{
Oligocone trichromacy: a rare and unusual cone dysfunction syndrome
}

\author{
M Michaelides, G E Holder, K Bradshaw, D M Hunt, J D Mollon, A T Moore
}

Br J Ophthalmol 2004;88:497-500. doi: 10.1136/bji.2003.028142

\begin{abstract}
Aim: To describe the phenotype of a case series of six patients with oligocone trichromacy.

Methods: The six affected individuals underwent an ophthalmological examination, electrophysiological testing and detailed psychophysical assessment.

Results: All six affected patients had a history of moderately reduced visual acuity $(6 / 12$ to $6 / 24)$ from infancy, not improved by full spectacle correction. They complained of mild photophobia and they were not aware of any colour vision deficiency. They had no nystagmus and fundi were normal. Electrophysiological testing revealed either absent/ profoundly reduced cone flicker responses or preserved but delayed and mildly reduced flicker responses. Colour vision was found to be within normal limits, but some patients showed mildly elevated discrimination thresholds along all axes.

Conclusion: The largest case series to date of patients with oligocone trichromacy is presented. The electrophysiological findings suggest that there may be more than one disease mechanism. The mode of inheritance is likely to be autosomal recessive, and while previous reports have suggested that this disorder is stationary, in one of these families there is clinical evidence of progression.
\end{abstract}

$\mathrm{T}$ he cone and cone-rod dystrophies are both clinically and genetically heterogeneous. The major clinical features of cone dystrophies are reduced visual acuity, abnormal colour vision, photophobia, central scotomata, and often nystagmus. Affected individuals may be symptomatic in infancy, but the majority present in childhood or early adult life. Cone dystrophies have been described with autosomal dominant, autosomal recessive, or $\mathrm{X}$ linked patterns of inheritance. ${ }^{12}$

In cone dysfunction syndromes one or more of the three cone types are deficient or absent. Patients generally have a congenital colour vision defect, which remains stationary during life. Several alterations of cone vision have been defined by the phenotypic changes in colour matches and colour discrimination: anomalous trichromacy, dichromacy, monochromatism, and achromatism. Complete achromats have no functioning cone photoreceptors, while incomplete achromats have residual colour vision. ${ }^{3}$

Oligocone trichromacy is a rare cone dysfunction syndrome, first described by Van Lith. ${ }^{4}$ It has been proposed that patients with oligocone syndrome have a reduced number of normal functioning cones (oligocone). It is characterised by reduced visual acuity and photophobia, reduced amplitude of the cone electroretinogram, a normal fundus, and colour vision within normal limits. ${ }^{2}{ }^{4}$ It would appear to be a stationary cone dysfunction with trichromacy.
We report the phenotype of six patients with oligocone trichromacy. We present electrophysiological data that suggest there may be more than one disease mechanism and propose that the disorder may be progressive at least in some individuals.

\section{PATIENTS AND METHODS}

After informed consent was obtained, six affected individuals from four different families were assessed. Families A and C contained two affected brothers and two affected sisters, respectively; family $\mathrm{B}$ contained a single male patient; and family D a single female patient. One or both parents from each family were also assessed. In addition, the grandmother of the two brothers in family A was also examined.

A full medical history was taken and ophthalmological examination performed. Electrophysiological assessment included an electro-oculogram (EOG), full field electroretinogram (ERG), and pattern ERG (PERG), incorporating the recommendations of the International Society for Clinical Electrophysiology of Vision. ${ }^{5-7}$ Colour vision testing included the use of the Hardy, Rand, and Rittler plates (HRR) (American Optical Company), Farnsworth-Munsell (FM) 100 hue test, Farnsworth D-15, the Mollon-Reffin (MR) minimal test, ${ }^{8}$ a computerised colour vision test, and anomaloscopy. The computerised test, which allows measurement of colour discrimination along tritan, deutan, and protan axes, has been described in detail previously. ${ }^{10}$ The FM 100 hue, Farnsworth D-15 and the MR test were all performed under CIE Standard Illuminant C from a MacBeth Easel lamp.

\section{RESULTS}

All six affected patients had a history of reduced visual acuity from infancy $(6 / 12$ to $6 / 24)$, not improved by full spectacle correction. They complained of mild photophobia, but were not aware of any colour vision deficiency. They had no nystagmus and fundi were normal.

In two sisters (cases 4 and 5) the cone flicker ERGs were severely reduced and there was a shorter latency than normal of the cone single flash ERG b-wave. Two brothers (cases 1 and 2) had absent cone ERGs. One patient (case 6) showed delayed and mildly reduced cone flicker ERGs with minimal photopic single flash ERG changes and a normal waveform maximal response. One patient (case 3) showed a delayed cone flicker ERG with a "double peak," an abnormal single flash cone ERG with the b-wave more affected than the awave and a mildly electronegative maximal response. Representative traces appear in figure 1. Clinical findings are summarised in table 1.

Both the father and 80 year old grandmother of the two brothers in family A were also examined. The father was found to have a visual acuity of 6/5 in both eyes, with normal colour vision, fundi, and electrophysiological testing. The grandmother complained of reduced visual acuity, which she had been aware of since the age of 50. Despite bilateral 


\begin{tabular}{|c|c|c|c|c|c|}
\hline Family & Case $^{*}$ & Age (years) & VA & Refractive error & Cone ERG \\
\hline A & 1 & 8 & $\begin{array}{l}6 / 12 \mathrm{RE} \\
6 / 18 \mathrm{LE}\end{array}$ & $\begin{array}{l}+2.0 /+1.50 \times 90 \\
+2.5 /+1.75 \times 90\end{array}$ & Absent cone ERG \\
\hline A & 2 & 6 & $\begin{array}{l}6 / 18 \mathrm{RE} \\
6 / 18 \mathrm{LE}\end{array}$ & $\begin{array}{l}+3.0 /+1.00 \times 90 \\
+3.5 /+1.25 \times 90\end{array}$ & Absent cone ERG \\
\hline B & 3 & 8 & $\begin{array}{l}6 / 12 \mathrm{RE} \\
6 / 12 \mathrm{LE}\end{array}$ & $\begin{array}{l}+1.25 /+1.5 \times 90 \\
+1.25 /+2.0 \times 90\end{array}$ & Reduced cone b:a wave ratio \\
\hline C & 4 & 14 & $\begin{array}{l}6 / 24 \mathrm{RE} \\
6 / 12 \mathrm{LE}\end{array}$ & $\begin{array}{l}-11.0 /-2.00 \times 30 \\
-8.5 /-3.00 \times 155\end{array}$ & Markedly reduced cone ERG \\
\hline C & 5 & 6 & $\begin{array}{l}6 / 24 \mathrm{RE} \\
6 / 24 \mathrm{LE}\end{array}$ & $\begin{array}{l}-8.0 /-1.50 \times 20 \\
-9.5 /-2.00 \times 110\end{array}$ & Markedly reduced cone ERG \\
\hline$D$ & 6 & 8 & $\begin{array}{l}6 / 24 \mathrm{RE} \\
6 / 36 \mathrm{LE}\end{array}$ & $\begin{array}{l}-13.0 /-1.5 \times 170 \\
-13.0 /-1.25 \times 10\end{array}$ & $\begin{array}{l}\text { Delayed and mildly reduced } \\
\text { cone ERG }\end{array}$ \\
\hline
\end{tabular}
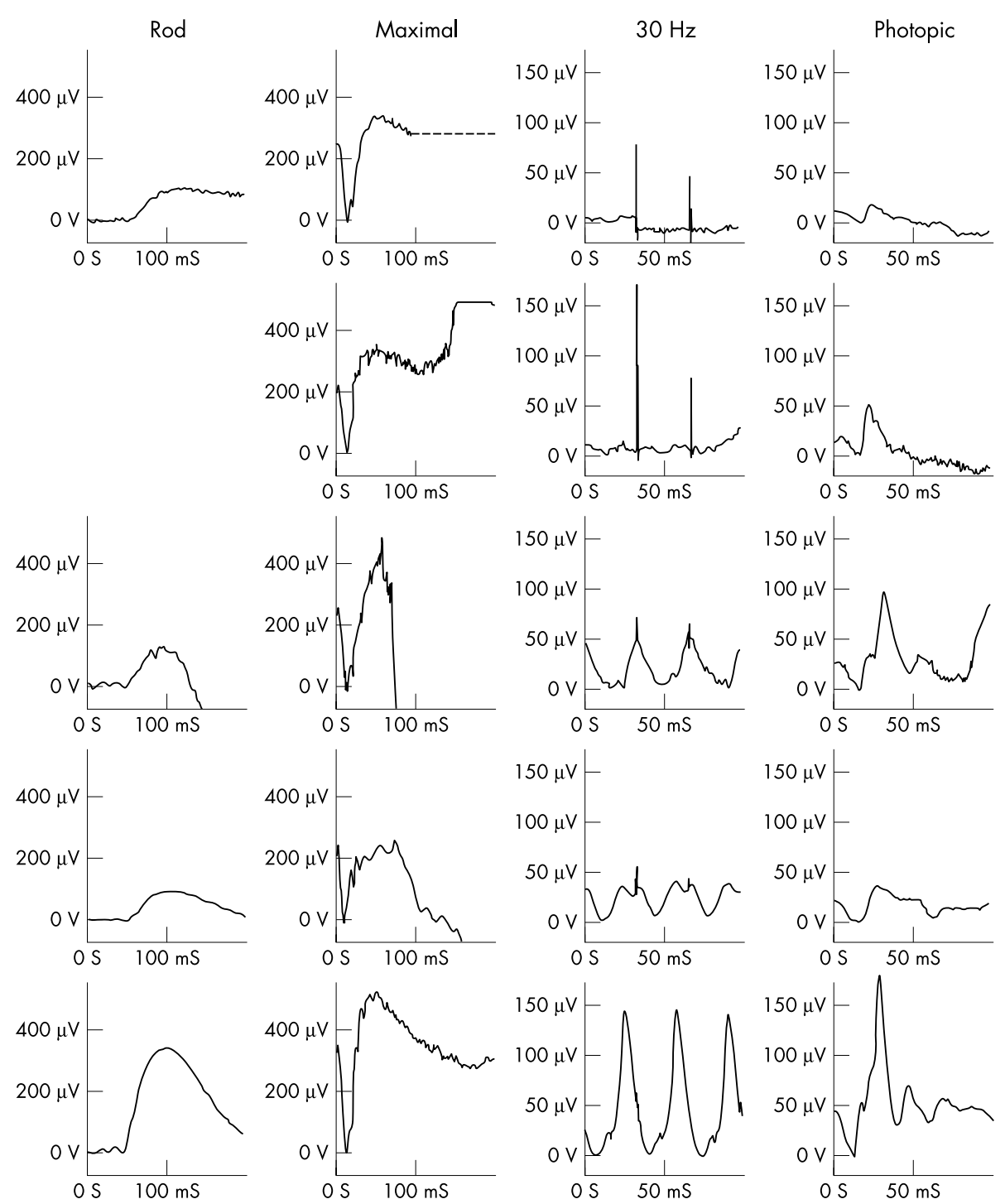

Figure 1 Full field ERGs in four patients. Data from a normal subject are shown for comparison (lower traces). Case 4 (upper traces) shows no definite rod specific abnormality; maximal response a-wave is mildly subnormal but of normal implicit time; cone single flash and flicker ERGs are severely reduced. Of interest, the b-wave implicit time is shorter than normal. Case 5 (second row) shows similar features; data for a rod specific response are unavailable. Case 6 (third row) has rod specific and maximal responses quantitatively similar to patients 1 and 2. Cone ERGs however are much better preserved; the flicker ERG is subnormal and also delayed with single flash cone photopic ERG showing only borderline abnormal b-wave implicit time. Case 3 (fourth row) has a rod specific response of abnormally low amplitude, but the maximal response shows a reduced b:a ratio suggesting dysfunction post-phototransduction. There is a delayed "double peaked" flicker ERG, and the short latency photopic b-wave seen in cases 4 and 5 is not present. 
cataract extractions in the past, her visual acuity was counting fingers in the right eye and $1 / 36$ in the left eye. Ophthalmoscopy revealed early "bull's eye" maculopathy in both eyes, whereas fundus examination of her grandsons was normal. ERG revealed absent cone responses, with normal rod function, indicating that she has a cone dystrophy (ERG data not shown). She has been unavailable for further psychophysical testing.

The six affected patients reported good colour vision and neither they nor their parents were aware of any colour vision abnormality. On examination, all had good colour vision. The various colour vision tests either revealed completely normal colour vision or slightly elevated discrimination thresholds. Anomaloscopy revealed matching ranges within normal limits, indicating the presence of long and middle wave cones of normal spectral sensitivity at the macula, while the absence of pseudoprotanomaly suggests that photopigment is present at normal optical densities in individual cone photoreceptors. One or both parents of all cases were tested and all had normal colour vision. The psychophysical findings are summarised in table 2 .

\section{DISCUSSION}

We report the largest case series to date of patients with oligocone trichromacy. The six patients in our series had moderately reduced visual acuity (6/12 to 6/24) and mild photophobia with normal visual fields and fundi. There was no nystagmus. Electrophysiological testing provided evidence of retinal dysfunction predominantly confined to the cone system.

Oligocone trichromacy was first described by Van Lith in 1973. ${ }^{4}$ Since then Keunen et al have described a further four patients, ${ }^{11}$ while Neuhann et al and, more recently, Ehlich et al have each reported a single case. ${ }^{12}{ }^{13}$ This rare cone dysfunction syndrome has previously been characterised by reduced visual acuity, mild photophobia, decreased amplitude of the cone ERG with normal rod responses, normal fundi, and normal or slightly reduced colour vision. Unlike our patients the two cases reported by Van Lith and Ehlich both had pendular nystagmus.

The cone ERG findings in our patients were poorly concordant. Cone flicker ERG responses were absent or markedly reduced in two siblings, who additionally showed a photopic b-wave of shortened implicit time. This may suggest some preservation of the cone OFF pathway, as the implicit time of the OFF response in normal subjects is similar to that in the two patients. Other patients showed clearly present but delayed and reduced cone flicker ERGs with one showing a mildly electronegative maximal response. The cone system implicit time changes are not expected in restricted disease, and are more usually associated with generalised dysfunction rather than loss of function. A post-receptoral processing abnormality may be present in some individuals, as suggested by the b:a ratio reductions. This phenotypic heterogeneity suggests that there may be more than one mechanism for disease pathogenesis, and thus that there may also be genetic heterogeneity associated with the oligocone phenotype.

Some patients in the present series had a mild reduction of colour discrimination, but no patient had markedly abnormal colour vision. Anomaloscopy revealed normal matching ranges, which indicates the presence of long and middle wave cones of normal spectral sensitivity and of normal optical density. The slightly elevated discrimination thresholds that were detected are compatible with a reduction in cone numbers.

It has been proposed that patients with oligocone trichromacy might have a reduced number of normal functioning cones (oligocone syndrome) with preservation of the three cone types in normal proportion, thereby enabling trichromacy. ${ }^{4}$ Keunen et al tested this hypothesis by screening foveal cone photopigment density in four patients with oligocone trichromacy. ${ }^{11}$ A reduced density difference of the foveal cone photopigment with a normal time constant of photopigment regeneration was found in all patients. Colour matching and increment threshold spectral sensitivity were normal. This provided supportive evidence for the hypothesis of a reduced number of foveal cones (decreased density differences) with otherwise normal functioning residual cones. Dysfunction of foveal cones alone will not affect the full field ERG. ${ }^{14}$ Peripheral retinal cones are also affected, as shown by the full field cone ERG abnormalities, profound in some patients, and our data do not support the hypothesis that the remaining cones function normally. Peripheral retinal colour vision in these patients would be of interest, as it may help establish whether peripheral colour discrimination is indeed reduced. Multifocal ERG may help determine whether central cone loss is "patchy" or "uniform."15

It has been thought likely that the mode of inheritance is autosomal recessive. However, both brothers and their paternal grandmother are affected in family A, more suggestive of autosomal dominant inheritance. As their father is unaffected there would need to be incomplete penetrance. Equally, previous reports have suggested this disorder to be stationary, but there is clinical evidence of progression in family A of this study, with worsening visual acuity and the development of "bull's eye" maculopathy in

Table 2 Summary of psychophysical findings

\begin{tabular}{|c|c|c|c|c|c|c|}
\hline Case & $\begin{array}{l}\text { Age } \\
\text { (years) }\end{array}$ & HRR & D-15 & Mollon-Reffin "minimal" test & Anomaloscope & Cambridge computerised colour test \\
\hline $1 \mathrm{~A}$ & 8 & All correct & Normal & $\begin{array}{l}\text { Slight elevation of discrimination } \\
\text { threshold along deutan axis }\end{array}$ & Normal range & $\begin{array}{l}\text { Slight elevation of discrimination thresholds } \\
\text { along all three colour axes }\end{array}$ \\
\hline $2 \mathrm{~A}$ & 6 & All correct & Normal & $\begin{array}{l}\text { Slight elevation of discrimination } \\
\text { threshold along deutan axis }\end{array}$ & Normal range & $\begin{array}{l}\text { Slight elevation of discrimination thresholds } \\
\text { along all three colour axes }\end{array}$ \\
\hline $3 B$ & 8 & All correct & & $\begin{array}{l}\text { Slight elevation of discrimination } \\
\text { thresholds along protan and deutan } \\
\text { axes }\end{array}$ & Normal range & $\begin{array}{l}\text { Slight elevation of discrimination thresholds } \\
\text { along all three colour axes }\end{array}$ \\
\hline $4 \mathrm{C}$ & 14 & All correct & Normal & Normal & Normal range & $\begin{array}{l}\text { Within the normal range along all three } \\
\text { axes }\end{array}$ \\
\hline $5 \mathrm{C}$ & 6 & 2 plates incorrect & 2 minor transpositions & Normal & Normal range & $\begin{array}{l}\text { Slight elevation of discrimination thresholds } \\
\text { along all three colour axes }\end{array}$ \\
\hline $6 \mathrm{D}$ & 8 & 1 plate incorrect & 2 minor transpositions & Normal & Normal range & $\begin{array}{l}\text { Slight elevation of discrimination thresholds } \\
\text { along all three colour axes }\end{array}$ \\
\hline
\end{tabular}


the older affected individual. However, until molecular genetic data become available it can not be proved that the grandmother's cone dysfunction is the same disorder as that of her two grandsons.

It has previously been suggested that oligocone trichromacy may represent a form of incomplete achromatopsia. It is therefore feasible that mutation within the three currently identified genes associated with achromatopsia, CNGA3, $C N G B 3$, and GNAT2, may underlie the molecular basis for this disorder. ${ }^{16-20}$ However, since oligocone trichromacy may have a developmental component, it is equally tempting to propose that genes involved in retinal photoreceptor differentiation, when cone numbers are being determined, also represent good candidate genes, rather than mutation within the three genes that encode cone specific intermediates within the phototransduction cascade. It is therefore possible that molecular genetic analysis of this disorder may help to shed light on cone photoreceptor development. Furthermore, since electrophysiological testing suggests that the site of abnormality may not be exclusively at the level of the photoreceptor, genes expressed preferentially in the inner retina may represent alternative candidates.

Oligocone trichromacy is perceived of as a rare disorder, and it has previously been proposed that patients have a reduced number of retinal cones that function normally. That may apply to central cones, but our data suggest that remaining peripheral cones do not function normally. Equally, as our six patients have been ascertained over a relatively short period of time ( 3 years), the disorder may be more common than previously recognised.

\section{ACKNOWLEDGEMENTS}

The work was supported by grants from the British Retinitis Pigmentosa Society and the Guide Dogs for the Blind Association. We are also grateful to the patients who kindly agreed to take part in this study and to Mr Dominic Heath who kindly referred us one of the families.

This work was presented at the European Paediatric Ophthalmology Society (EPOS) annual meeting, October 2002.

\section{Authors' affiliations}

M Michaelides, D M Hunt, A T Moore, Institute of Ophthalmology, University College London, 11-43 Bath Street, London ECIV 9EL, UK G E Holder, Moorfields Eye Hospital, City Road, London ECIV 2PD, UK K Bradshaw, Department of Ophthalmology, Addenbrooke's Hospital, Cambridge CB2 2QQ, UK

J D Mollon, Department of Experimental Psychology, University of Cambridge, Downing Street, Cambridge CB2 3EB, UK
Correspondence to: Professor A T Moore, Institute of Ophthalmology, University College London, 1 1-43 Bath Street, London EC1V 9EL, UK; tony.moore@ucl.ac.uk

Accepted for publication 1 September 2003

\section{REFERENCES}

1 Goodman G, Ripps H, Siegel IM. Cone dysfunction syndromes. Arch Ophthalmol 1963;70:214-31.

2 Simunovic MP, Moore AT. The cone dystrophies. Eye 1998;12:553-65.

3 Pokorny J, Smith VC, Verriest G, et al. Congenital and acquired color vision defects. New York: Grune and Stratton, 1979

4 van Lith GHM. General cone dysfunction without achromatopsia. In: Pearlman JT, eds. 10th ISCERG Symposium. Doc Ophthalmol Proc Ser 1973;2:175-80.

5 Marmor MF, Zrenner E. Standard for clinical electroretinography (1999 update). Doc Ophthalmol 1998;97:143-56.

6 Bach M, Hawlina M, Holder GE, et al. Standard for pattern electroretinography. International Society for Clinical Electrophysiology of Vision. Doc Ophthalmol 2000;101:11-18.

7 Marmor MF, Zrenner E. Standard for clinical electro-oculography. International Society for Clinical Electrophysiology of Vision. Arch Ophthalmol 1993;111:601-4.

8 Mollon JD, Astell S, Reffin JP. A minimalist test of colour vision. In: Drum B, Moreland JD, Serra A, eds. Colour vision deficiencies X. Amsterdam: Kluwer Academic Publishers, 1991:59-67.

9 Mollon JD, Reffin JP. A computer-controlled colour vision test that combines the principles of Chibret and of Stilling. J Physiol 1989;414:5.

10 Regan BC, Reffin JP, Mollon JD. Luminance noise and the rapid determination of discrimination ellipses in colour deficiency. Vis Res 1994;34:1279-99.

11 Keunen JEE, De Brabandere SRS, Liem ATA. Foveal densitometry and color matching in oligocone trichromacy. In: Drum B, Moreland JD, Serra A, eds. 12th IRGCVD Symposium, Colour vision deficiencies XII. Amsterdam: Kluwer Academic Publishers, 1995:203-10.

12 Neuhann T, Krastel H, Jaeger W. Differential diagnosis of typical and atypical congenital achromatopsia. Analysis of a progressive foveal dystrophy and a nonprogressive oligo-cone trichromacy (general cone dysfunction without achromatopsia), both of which at first had been diagnosed as achromatopsia. Albrecht Von Graefes Arch Klin Exp Ophthalmol 1978;209:19-28.

13 Ehlich P, Sadowski B, Zrenner E. Oligocone trichromasy, a rare form of incomplete achromatopsia. Ophthalmologe 1997;94:801-6.

14 Holder GE. Pattern electroretinography (PERG) and an integrated approach to visual pathway diagnosis. Prog Retin Eye Res $2001 ; 20: 531-61$

15 Hood DC. Assessing retinal function with the multifocal technique. Prog Retin Eye Res 2000; 19:607-46.

16 Kohl S, Marx T, Giddings I, et al. Total colourblindness is caused by mutations in the gene encoding the alpha-subunit of the cone photoreceptor cGMPgated cation channel. Nat Genet 1998;19:257-9.

17 Sundin $\mathrm{OH}$, Yang J-M, Li Y, et al. Genetic basis of total colourblindness among the Pingelapese islanders. Nat Genet 2000;25:289-93.

18 Kohl S, Baumann B, Broghammer M, et al. Mutations in the CNGB3 gene encoding the beta-subunit of the cone photoreceptor cGMP-gated channel are responsible for achromatopsia (ACHM3) linked to chromosome 8q21. Hum Mol Genet 2000;9:2107-16.

19 Aligianis IA, Forshew T, Johnson S, et al. Mapping of a novel locus for achromatopsia (ACHM4) to $1 \mathrm{p}$ and identification of a germline mutation in the $\alpha$ subunit of cone transducin (GNAT2). J Med Genet 2002;39:656-60.

20 Kohl S, Baumann B, Rosenberg T, et al. Mutations in the cone photoreceptor G-protein alpha-subunit gene GNAT2 in patients with achromatopsia. Am J Hum Genet 2002;71:422-5. 